\title{
Sustainable solar home systems model: Applying lessons from Bangladesh to Myanmar's rural poor
}

Newcombe, Alex; Ackom, Emmanuel

Published in:

Energy for Sustainable Development

Link to article, DOI:

10.1016/j.esd.2017.03.002

Publication date:

2017

Document Version

Peer reviewed version

Link back to DTU Orbit

Citation (APA):

Newcombe, A., \& Ackom, E. (2017). Sustainable solar home systems model: Applying lessons from Bangladesh to Myanmar's rural poor. Energy for Sustainable Development, 38, 21-33.

https://doi.org/10.1016/j.esd.2017.03.002

\section{General rights}

Copyright and moral rights for the publications made accessible in the public portal are retained by the authors and/or other copyright owners and it is a condition of accessing publications that users recognise and abide by the legal requirements associated with these rights.

- Users may download and print one copy of any publication from the public portal for the purpose of private study or research.

- You may not further distribute the material or use it for any profit-making activity or commercial gain

- You may freely distribute the URL identifying the publication in the public portal

If you believe that this document breaches copyright please contact us providing details, and we will remove access to the work immediately and investigate your claim 


\section{Sustainable solar home systems model: Applying lessons from Bangladesh to Myanmar's rural poor 1.0 Introduction}

Roughly 36 million people in Myanmar, equivalent to $68 \%$ of the population lacked access to electricity in 2013 (IEA, 2015). In terms of access in rural areas, Myanmar, is ranked among the lowest in the world with electrification rate of $28.4 \%$ in 2010 (Index Mundi, 2015). More recent data on rural electrification rates appears unavailable. The lack of access to electricity areas in rural areas is especially compounded by the geographic remoteness of such communities and relatively low income. Access to modern energy services such as electricity is reported to be intrinsically linked to , income generation, economic development, agricultural productivity, gender and safety issues, access to water, health, education, and overall, a better quality of life (Pode, 2015).This has been confirmed, in part by the "Energy Plus" model - which was first reported by United Nations Development Programme (UNDP)-that combining access to electricity with capacity development and productive uses of electricity for income generation can help guarantee the ability to pay for electricity services, ensure longevity of the intervention and overall, improvement in livelihood (Velumail, 2016; Larsen et.al, 2016; UNDP, 2012) .

Two key terms - electricity access and rural population- often used throughout this paper have been briefly defined. Firstly, it is important to recognize the non-binary nature of electricity access. For example, having access to electricity goes beyond whether a household is electrified or not. Rather it encompasses issues such as reliability, affordability and productive use of that energy, all play crucial roles in determining the extent of access to energy services (GNESD, 2014; Singh, et. al. 2014)). Secondly, the paper focuses on rural populations in Myanmar based on the definition employed by national statistical offices.

This objectives of this paper are to:

(i) analyse lessons learned from experience with Grameen Shakti-IDCOL in Bangladesh and similar initiatives,

(ii) identify barriers to sustainable electrification for rural areas of Myanmar,

(iii) apply these lessons learned from Grameen Shakti-IDCOL to rural poor in Myanmar, and

(iv) offer policy recommendations to overcome identified barriers to sustainable electrification for rural poor in Myanmar

$\begin{array}{lc}\text { Abbreviations } & \\ \text { CFL } & \text { Compact Fluorescent Lamp } \\ \text { DRD } & \text { Department of Rural Development } \\ \text { IDCOL } & \text { Infrastructure Development Company Limited } \\ \text { LCOE } & \text { Levelised cost of electricity } \\ \text { LED } & \text { Light emitting Diode } \\ \text { MFI } & \text { Microfinance Institution } \\ \text { MLFRD } & \text { Ministries of livestock, fisheries and rural development } \\ \text { MOEP } & \text { Ministries of electric power } \\ \text { MV/HH } & \text { Medium Voltage per household } \\ \text { NEP } & \text { National Electrification Plan } \\ \text { NGO } & \text { Non-governmental organisation } \\ \text { PO } & \text { Partner organisation } \\ \text { PPP } & \text { Public Private Partnership } \\ \text { RET } & \text { Renewable energy technologies } \\ \text { SHS } & \text { Solar home systems }\end{array}$




\subsection{Scope and methodology of report}

The paper was achieved through a desktop literature analysis. Several literature from various sources were reviewed including academic, institutional, newspaper articles, organisational reports and national policy documents. The paper begins with a review of the current situation in Myanmar, outlining the demographic of the rural poor population in Myanmar, current electricity access and electrification plans. This is followed by, analyses and lessons learned from Grameen Shakti-IDCOL model with the goal of exploring potential applicability to the Myanmarn case. Through compilation, review, and analysis of several literature, this paper contribute knowledge (which otherwise is absent) on how the Myanmarn situation could benefit from the experience of the Grameen ShaktiIDCOL model to address barriers in SHS deployment through a microfinance based public private partnership (PPP) initiatives.

\subsection{Background Review}

\subsection{Rural poor demographic in Myanmar}

This section aims to describe the target demographic of rural poor in Myanmar, to get a better understanding of their quality of life and energy use. Bordering China, Thailand, India and Bangladesh, Myanmar has an area of $676,578 \mathrm{~km} 2$, and a population of $53,437,159$ as of 2014 , of which roughly two thirds live in rural areas (Index Mundi, 2015). The rural population has seen an increase of $12 \%$ since 1990, which is dwarfed in comparison to the urban growth in the same period of $73 \%$ (Index Mundi, 2015).

The rural population is characterised by higher poverty rates than the urban areas and less access to electricity. The (rural and urban) national poverty is not very 'deep' in that only $1.7 \%$ of the population is under US\$1.25/day (PPP) but is very 'wide' as $26.5 \%$ is under US\$2.00/day (PPP). The poverty in rural areas however was a factor of 1.8 times greater than urban areas in 2010 (compared to 1.6 times in 2005). There has been great GDP growth (between $11.3 \%-13.8 \%$ in $2001-2008$ ) but also excessive inflation, which results in the average person seeing only slightly more disposable income in 2010 than in 2005 (Schmitt-Degenhardt, 2013). For example, rice accounts for $20 \%$ and $22 \%$ of total consumption expenditure in urban and rural areas respectively (Okamoto et al, 2003). Over $50 \%$ of households are engaged in agriculture as the main business (Schmitt-Degenhardt, 2013). According to UNFPA, (2010), "about two thirds of poor households work in the agriculture sector and most own and/or farm small land or are landless". While roughly $32 \%$ of the national population of Myanmar had access to electricity as of 2013 (IEA, 2015), the rates of rural electrification in Myanmar have increased from 20\% in 1990 to 24\% in 2000 and to $28.4 \%$ in 2010 (Index Mundi, 2015). However, the total rural population without access to electricity still stands at approximately 25.6 million, roughly half the population of Myanmar. Up to $93 \%$ of households in Myanmar use traditional biomass such as firewood for cooking (IEA, 2015). Myanmar currently contributes very little to climate change as the per capita electricity consumption is extremely low, however as electrification rates increase, greenhouse gas emissions will follow. 




Figure 1: Map of Myanmar with administrative divisions. Credit: http://myanmarmap.facts.co

Myanmar is divided into 21 administrative divisions as shown in Figure 1, which include seven states, seven regions, one union territory, five self-administered zones and 1 self-administered division. The Yangon region is the most populated, where approximately $14 \%$ of the population resides in $1.5 \%$ of the area. Poverty is higher in the Ayeyarwady and Rakhine regions, and lower in Bago (West) and Kayah. The highest poverty gap was observed in the Chin speaking people, and the lowest in the Kayah speaking people. Low utilities (energy, transport and phone) were observed in the Bago and Chin regions, whereas high access to utilities were observed in the Magway region. It was observed that household indebtedness was a greater problem in the Bago (East) and Chin regions, whereas it was less of a problem in Bago (West), Shan (East) and Shan (North). Drought, followed by pests and floods were seen to be the most significant problem, as they impact the livelihoods of the majority of people (Schmitt-Degenhardt, 2013). It is worth noting that the situation is likely to be more vulnerable with climate change, as for the third consecutive year, Myanmar was ranked as the second most vulnerable country in the world to extreme weather events (Government of Myanmar, 2015).

\subsection{Current status of electricity in Myanmar}

The status of electricity in Myanmar is characterised by a low electrification ratio, electricity shortage in the dry season due to an overdependence on hydroelectric power plants, increasing demand, high technical and non-technical losses in transmission and distribution, and remote geographical areas which are difficult to access and costly to connect to the grid (Nai, 2014). These 
topics are discussed in this section to give an overview of the current status of electricity in Myanmar.

Myanmar has the lowest energy consumption per capita in Asia, due mainly to low electrification rates, low industrial development, and a lack of investment (Asian Development Bank, 2015). As can be seen from Table 1, the per capita consumption of electricity in Myanmar is growing rapidly, but still very low compared to neighbouring countries such as India (World Bank, 2016). For electricity, consumption comprised of $2015 \mathrm{GWh}$ for households, $1850 \mathrm{GWh}$ for industrial, $1071 \mathrm{GWh}$ for commercial and $57 \mathrm{GWh}$ for small lighting (MOEP, 2013a). However biomass accounts for roughly $80 \%$ of the country's total final energy consumption, and about $70 \%$ of households depending on diesel, kerosene, batteries or candles for lighting (Pode, 2015; IGES, 2014).

\begin{tabular}{|l|l|l|}
\hline $\begin{array}{l}\text { Electric Power Consumption } \\
\text { (kWh per capita) }\end{array}$ & 2006 & 2012 \\
\hline Myanmar & 86.5 & 152.7 \\
\hline Bangladesh & 191.6 & 278.6 \\
\hline Cambodia & 80.4 & 206.5 \\
\hline India & 510.7 & 743.7 \\
\hline Indonesia & 519.5 & 729.9 \\
\hline
\end{tabular}

Table 1: Electric power consumption per capita in 2006 and 2012 in Myanmar, Bangladesh, Cambodia, India and Indonesia

The electricity network or grid in Myanmar covers only 5.3\% of the country's 62,218 villages, mostly in the central part of Myanmar, along the highway from Yangon to Mandalay, whereas $20.5 \%$ of villages are electrified by off-grid means, leaving around $74 \%$ of villages un-electrified (IGES, 2014). Of the villages with access to off-grid electricity, $73 \%$ are by diesel generators, $13 \%$ to mini hydro systems, with roughly $7 \%$ each to solar and biomass or biogas systems (DRD, 2014). By number of households it is estimated that over 7 million households have no electricity while 3 million households do (Columbia University, 2014). A breakdown is given below of the states and regions by grid electrification, off-grid electrification and un-electrified number of villages is shown below, with the percentage representing the sum of population (not numbers of villages) with access to grid and off-grid electrification (IGES, 2014).

\begin{tabular}{|l|l|l|l|l|}
\hline State/Region & $\begin{array}{l}\text { \% } \\
\text { population } \\
\text { with } \\
\text { access to } \\
\text { electricity }\end{array}$ & $\begin{array}{l}\text { Grid (\# } \\
\text { of } \\
\text { villages) }\end{array}$ & $\begin{array}{l}\text { Off-grid } \\
\text { (\# of } \\
\text { villages) }\end{array}$ & $\begin{array}{l}\text { Un-electrified } \\
\text { (\# of villages) }\end{array}$ \\
\hline Kayar Region & 41 & 53 & 42 & 416 \\
\hline Mandalay Region & 35 & 738 & 189 & 2313 \\
\hline Mon State & 31 & 254 & 318 & 628 \\
\hline Kachin State & 26 & 1 & 283 & 2295 \\
\hline Bago Region & 23 & 309 & 2070 & 2416 \\
\hline Kayin State & 23 & 46 & 79 & 1938 \\
\hline Sagaing Region & 22 & 624 & 3060 & 2295 \\
\hline Chin State & 16 & - & 326 & 1026 \\
\hline Ayarwadi Region & 10 & 343 & 2992 & 8602 \\
\hline Shan State & 9 & 374 & 786 & 13424 \\
\hline
\end{tabular}




\begin{tabular}{|l|l|l|l|l|}
\hline Tanintharyi Region & 9 & 573 & 1611 & 2588 \\
\hline Rakhine State & 6 & - & 1033 & 2827 \\
\hline
\end{tabular}

Table 2: States and regions of Myanmar, with \% of population with electricity access, and number of villages with grid electricity, off-grid electricity and un-electrified (IGES, 2014)

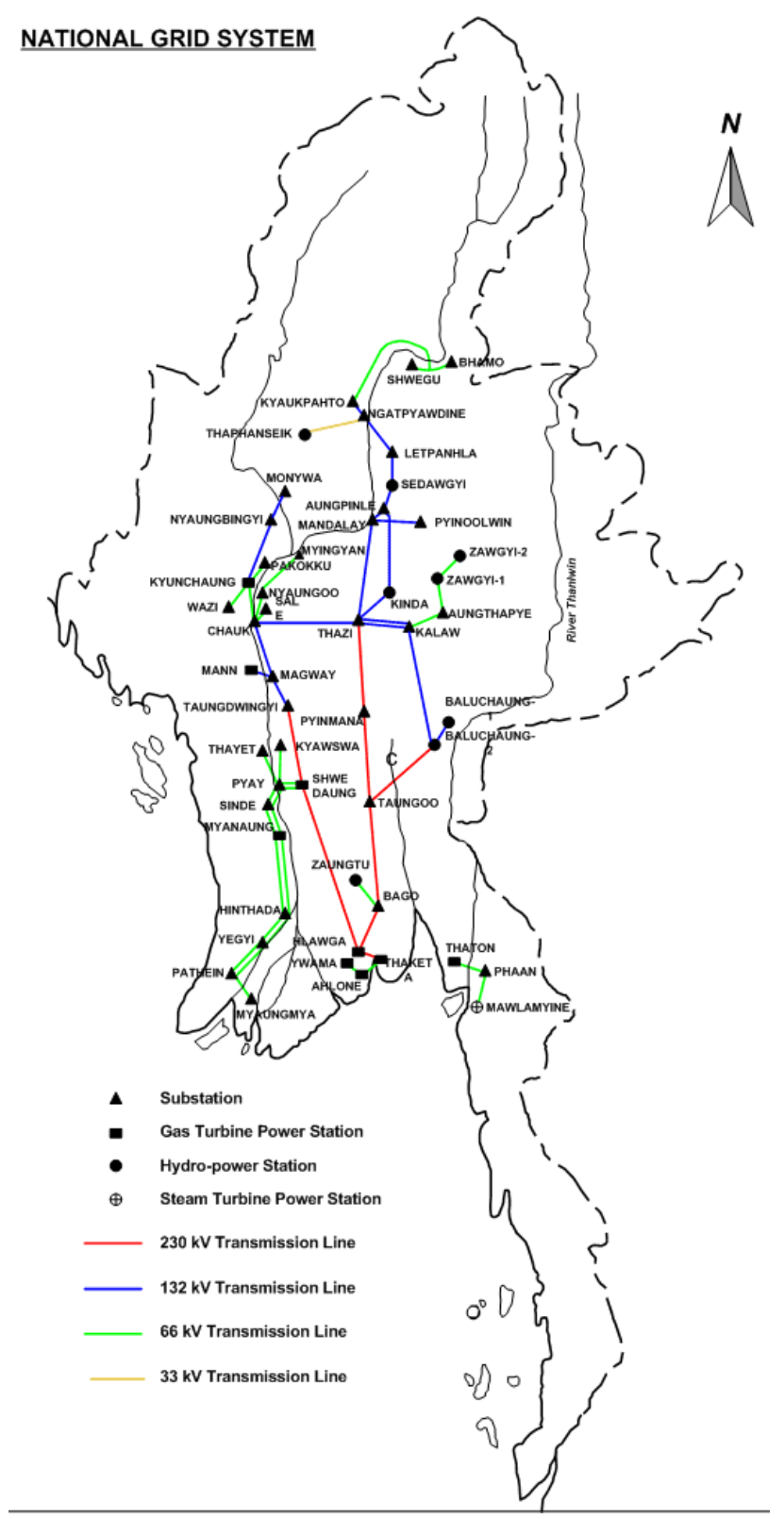

Figure 2: The existing grid networks and power stations of Myanmar Credit: geni15.wrsc.org

As can be seen in Figure 2, Myanmar's electricity network is focused on the densely populated Yangon, Naypyitaw and Mandalay regions. The transmission lines consist of $3979 \mathrm{~km}$ of $230 \mathrm{kV}$, $2334 \mathrm{~km}$ of $132 \mathrm{kV}, 3729 \mathrm{~km}$ of $66 \mathrm{kV}$ and $27 \mathrm{~km}$ of $33 \mathrm{kV}$, and currently Myanmar is not connected to any of its five neighbours (Bangladesh, India, China, Lao PDR and Thailand) (MOEP, 2013a). As of the end of 2016, there would be $2760 \mathrm{MW}$ of installed hydropower capacity, 420MW of coal, 3593MW 
of Gas and 50MW of solar (MOEP, 2013a). This reliance on hydropower means that in the dry season Myanmar lacks approximately $500 \mathrm{MW}$ of demand, whereas in the wet season there is approximately $180 \mathrm{MW}$ of surplus supply (MOEP, 2013b). In addition to this, Yangon experiences load shedding of up to 5 hours in the wet season, with even more in the dry season (Kumar et al., 2015). Myanmar experiences high transmission losses of 6-7\%, high distribution losses of approximately $20 \%$ due to overloading and commercial losses (Columbia University, 2014).

Off-grid electricity projects are developed by both the government (Department of Rural Development) and private sector. Many donor-funded projects have been installed, e.g. funded by the Asian Development Bank (ADB), United Nations Development Programme (UNDP) and the United Nations Industrial Development Organisation (UNIDO) (IGES, 2014). In addition, off-grid projects are being implemented by village level committees or by local private developers (IGES, 2014).

\subsection{Myanmar's electricity future}

It is important to describe Myanmar's plans for the future of the energy sector, to see how sustainable energy could play a role in electrification for the rural poor. According to (MOEP, 2013a), the "aims and objectives of the energy sector policy are to:

- Ensure energy security as a basis for sustainable economic development

- Provide reliable and affordable energy supply to all possible categories of consumers

- Achieve the Myanmar national government's overarching objective of poverty reduction

- Improvement of quality of life of its people

- Increase energy exports for foreign exchange earnings (after the national demand is met)

- Increase community-based projects focused on renewable energy, with increased women participation, to provide income and/or livelihood opportunities to rural poor populations

- Progressively decrease use of fossil-fuel dependent energy infrastructure"

Rapid growth in electrification in a developing country context, achieved primarily through increased efficiency and effectiveness in a coordinated sector wide approach such as in Rwanda has been indicated as an ideal model for Myanmar to emulate (Columbia University, 2014). This can be done by including implementation efforts which are in line with an economical, least cost planning strategy, and planning both financial and physical resources to be mobilised in a predictable and structured fashion over a number of years (Columbia University, 2014).

Myanmar's National Electrification Plan (NEP) has an aggressive grid electrification rollout program and an ambitious off grid program, with a total required investment at approximately US\$ 5.8 billion, not including additional generation and transmission capacity costs (World Bank, 2014a). The World Bank Energy Program for Myanmar will offer up to US\$1 billion in 2014-2016 to scale up access to reliable electricity supply, improve efficiency and sustainability of the electricity system (World Bank, 2014a).

The NEP aims at $47 \%$ electricity access by $2020,76 \%$ by 2025 , and $100 \%$ by 2030 (World Bank, 2014a). The demand has increased for roughly $15 \%$ for each year since 2011 , and is expected to increase at roughly this rate in the near future (Win, 2013; DRD, 2015). Neighbouring countries such as Thailand, Vietnam and China have managed to increase electricity coverage from $30 \%$ to $100 \%$ within two decades, and to achieve the same, Myanmar is required to double the current average 
annual electrification rate (Columbia University, 2014). In addition, Myanmar aims to increase the share of non-hydro renewables to $15-18 \%$ of total installed capacity by 2020 (Pode, 2015; Myint, 2012).

One of the most comprehensive electrification planning documents in Myanmar is the geospatial least cost electrification rollout plan by Columbia University and funded by the World Bank (Columbia University, 2014). This plan utilises a combination of technical, financial and geographic information, such as medium voltage grid line locations, geo-located populated places, technology specifications, technology costs, and other values used for system costs and energy demand. For this study, metres of medium voltage line per household connection is a key metric $(\mathrm{MV} / \mathrm{HH})$, since in sparsely populated areas such as most of the Shan and Chin states, there is a sharp increase in length of medium voltage wire required per household and therefore also required investments per household. At US\$20,000/ $\mathrm{km}$ for MV line, it becomes a significant factor in the least cost planning aspect. Also considered to grid connection were solar powered mini-grids and Solar Home Systems (SHSs). Mini-grids were assumed to cost approximately US\$1400 per household, and can supply 250 kWh per household, which was $25 \%$ of the assumed annual household consumption (1000 kWh per household, roughly six times the current energy per capita consumption, which was a conservative estimate considering average household size of 5 people per household, and the rapidly increasing energy demand). 80-100Wp SHSs can provide around 150-175 kWh/year, using an assumed cost of only US\$450-500 per household (Columbia University, 2014).

Based on the assumptions used in that study, findings indicate that grid extension is the best option for 7,220,000 households, whereas mini-grid and SHS are recommended only for 2,700 and 1,900 households respectively (Figure 3 ). This would require roughly $62,000 \mathrm{~km}$ of MV line, which is separated into 5 phases with an equal length of total MV line, each increasing with $\mathrm{km}$ of MV line per household and thus cost to each household, i.e. phase 1 includes 3,510,000 households and $12,300 \mathrm{~km}$ of MV line at $\$ 700 /$ household and $4 \mathrm{~m} \mathrm{MV} /$ household, whereas phase 5 includes only 234,000 households and $12,300 \mathrm{~km}$ of MV line at $\$ 1,710 /$ household and $54 \mathrm{~m} \mathrm{MV/household.} \mathrm{The}$ average length of $\mathrm{MV}$ line per household is only 9 metres, but there is a wide variation between households in the $1^{\text {st }}$ and $5^{\text {th }}$ phase, as the households are more remote with increasing phases. This would require double the existing capacity of generation, and accelerating the grid connection rates by a factor of 10 . The full grid electrification is expected to take at least 15 years, and since the highest costs areas (phase 5 and 4) have urgent need for basic power for lighting, clinics and schools, there is a need for temporary or transitional electrification options, called in the plan "Preelectrification", which targets 250,000 households mostly in Shan and Chin states (95,000 for SHS \& 155,000 for mini-grid), mostly from phase 4 and phase 5 . This is designed so that SHS supplies villages with less than 50 households, and mini-grids for villages with more than 50 households, and these villages could be integrated to grid later on and save on distribution investment if built to grid standard (Columbia University, 2014). 


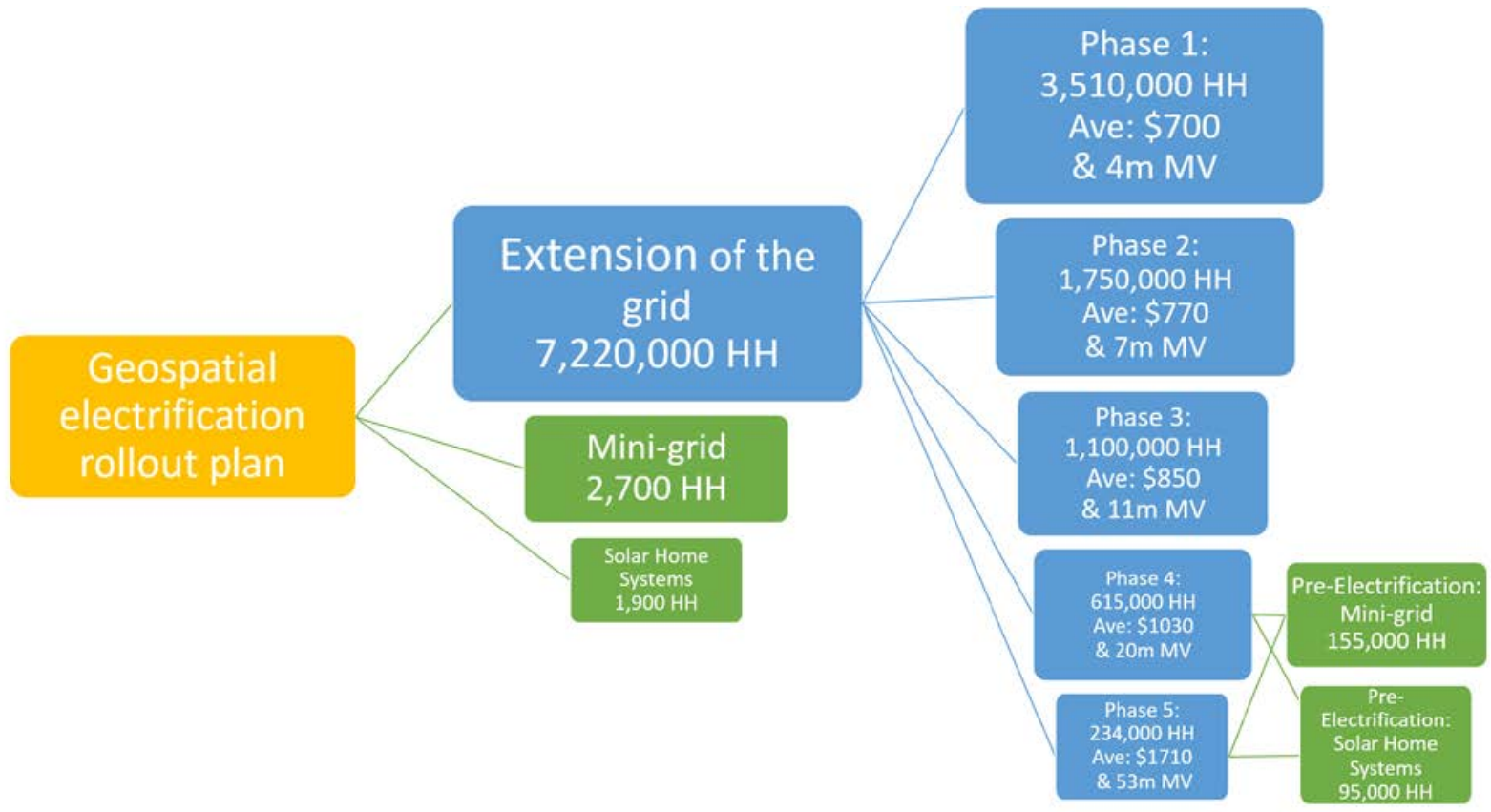

Figure 3: Electrification designations from the geospatial electrification rollout plan including average cost and length of medium voltage lines per household

The World Bank has given a US\$ 400M interest free loan (with service fee of $0.75 \%$ ), to help in the provision of technical and financing assistance for electrification in Myanmar (Myanmar Times, 2015). Of this, roughly three quarters is designated towards the grid rollout program, $20 \%$ to the offgrid pre electrification program and $5 \%$ towards capacity building and technical assistance. With the current tariff structure, the funding gap (revenue + loan received - capex, opex and loan repayment) of the electricity grid extension over a 40 year period at the current tariff $(0.037 \$ / \mathrm{kWh})$ is at $\$ 2.2$ billion, showing little incentives for private investors. As a simple comparison, this funding gap would be reduced to $\$ 0.25$ billion by implementing neighbouring Vietnam's residential tariff for example $(\$ 0.047 / \mathrm{kWh})$. This shows a clear and strong need for a review of the electricity tariff and subsidy mechanisms.

According to Myint (2012) and DRD (2015), some of the main barriers or limitations in the energy future of Myanmar include:

- The subsidy policy is ineffective and inefficient and needs reform

- Lack of financial incentives for private investors

- Lack of effective quality and efficiency standards

- Energy efficient products are expensive due to a limited market

- Lack of rural electrification law

- Lack of regulation for mini-grid systems

The potential of the IDCOL-Grameen Shakti model to overcome these barriers is further discussed in section 2.4 . 


\subsection{Experience from Grameen Shakti/IDCOL and potential to adapt model to Myanmar}

Inspiration for a sustainable microfinance-based solar home system model can be found from Myanmar's neighbour Bangladesh. Similar to Myanmar, a large portion of Bangladesh's 160 million do not have access to electricity and use kerosene or diesel lamps. Other factors common to both countries are a dispersed rural population, difficult topography and therefore expensive grid expansion, consistent and sufficient solar irradiation, restricted rural demand, presence of NGOs and Micro-Finance Institutions (MFIs), and a stable national economic growth outlook in terms of GDP. Bangladesh, mostly through the collaborative efforts of IDCOL and Grameen Shakti, have managed to implement microfinance based solar home systems on a large scale, exceeding expectations.

IDCOL, the Infrastructure Development Corporation, is a government owned financial institution dedicated to promote and finance infrastructure and renewable energy projects in Bangladesh, and operates as a private company. IDCOL was founded by the government and combines government capital and private sector management to produce a successful PPP (ArcFinance, 2014). IDCOL initially received funding support from the World Bank and GEF, among others (ArcFinance, 2014). In numbers, IDCOL's achievements by December 2014 are listed below.

\begin{tabular}{|l|l|}
\hline SHS installed (millions) & 3.45 \\
\hline Consumers reached (millions) & 15.5 \\
\hline Installed capacity (MW) & 141 \\
\hline Fossil fuels avoided per year (tons) & 207,000 \\
\hline $\begin{array}{l}\text { CO2 emissions avoided per year } \\
\text { (tons) }\end{array}$ & 488,913 \\
\hline Number of jobs & 75,000 \\
\hline Investment (US\$ millions) & $\$ 600$ \\
\hline
\end{tabular}

Table 3: Statistics of achievements by IDCOL (Haque, 2015)

It should be noted that 3 million of the 3.45 million SHS were installed from 2010-2014. The structure involves funding from IDCOL, the government and development partners, which is then provided to an NGO/partner organisation (PO) in the form of grants or loans (Figure 4). The NGO/PO then sells the SHS and provides service to households, in return for down-payments and loan instalments. The NGO/PO buys the components from a supplier, after the supplier has been approved by a technical standards committee (Figure 4). NGOs/POs also receive financial and technical capacity building assistance from IDCOL. Currently there are 47 POs which have partnered IDCOL, with Grameen Shakti being by far the most dominant one, having a market share of $56 \%$ by 2013. IDCOL uses a subsidy targeted with more for the poor, with a fixed subsidy scheme meaning poorer households get a larger percentage of subsidy. A strong point of this model is the price determination by the market, as there are many competing suppliers for each component of the SHS, which is passed on to the customers, as POs are allowed to obtain SHSs at low and competitive prices. 


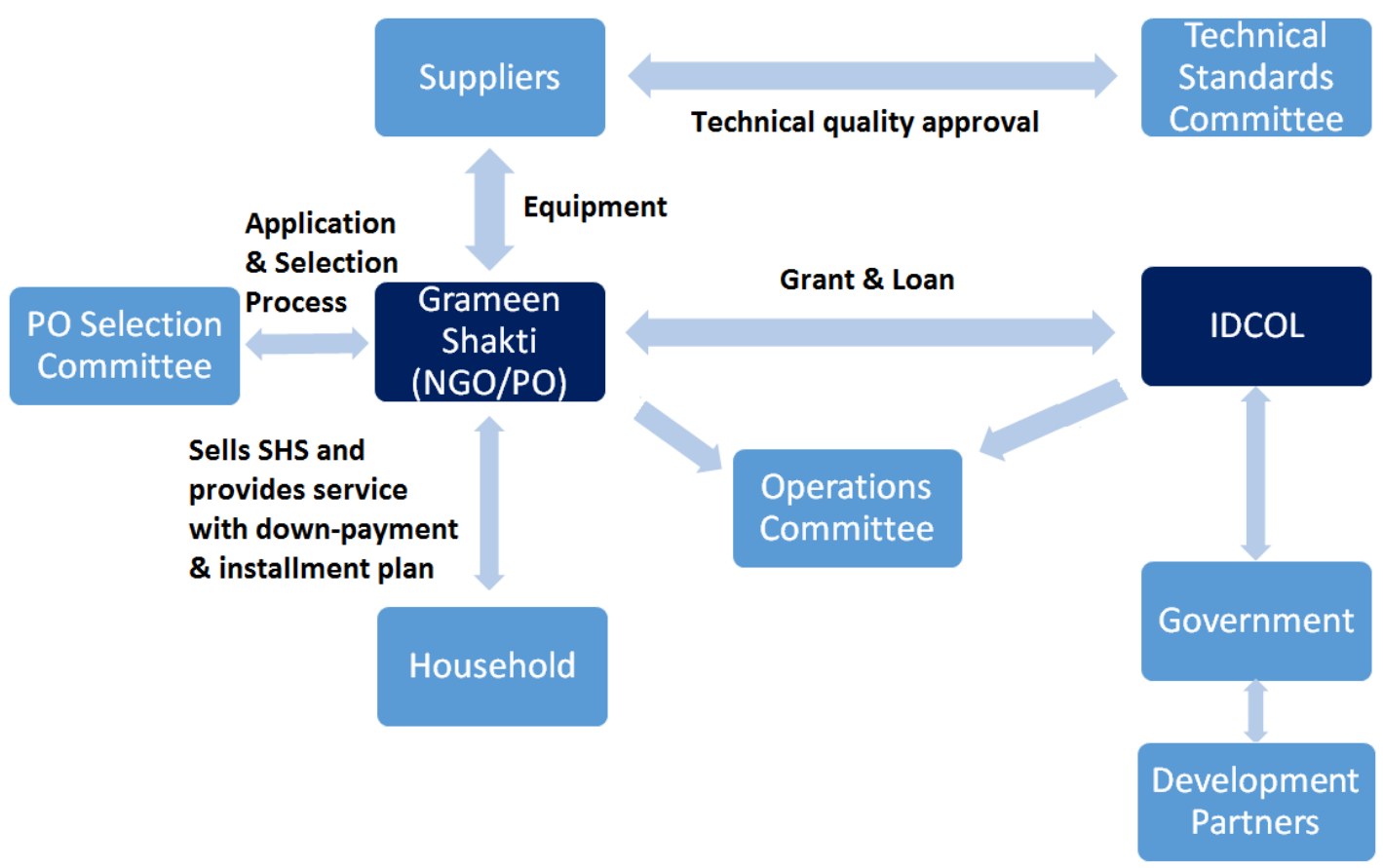

Figure 4: Operational structure of IDCOL (Haque, 2015).

Grameen Shakti (GS) is an exemplary NGO with affordable financing methods. A 50Wp SHS, after grant, $15 \%$ upfront cost and $12 \%$ annual service charge, can be purchased from GS for US\$10.97 a month for 3 years. Here it can be seen that the customer pays essentially the same amount as half a litre of kerosene or diesel a night, but receives ownership of a SHS, which not only produces better light than the lamp, for reading and other uses, but also may allow charging of mobile phones and other electric appliances (Terrapon-Pfaff et al., 2014). Repair and maintenance service is included in the service charge for the customers for the length of the payment period. This after sale service is required by IDCOL for a minimum of 3 years. Once the period is over, customers have the option to enter into a yearly repaid and maintenance service contract for an annual cost, however most don't as they can address the issues themselves after the one day training they receive. GS has also created a social business program which trains primarily women in Grameen Technology Centres that are situated through the regions of interest. Women become trained social entrepreneurs, able to build system components and sell them back to GS and also maintain the systems (Laufer \& Schafer, 2011). They are able to work mostly from home and have relatively well paying jobs. GS buys equipment from suppliers, and then sells the system to households. It should be mentioned that, in addition to meeting the basic lighting demands of rural households, SHSs also have potential to enhance women's empowerment in Myanmar, according to Pascale (2016).

The several barriers and limitations in Myanmar's electricity future mentioned in section 2.3 are linked to the Grameen Shakti-IDCOL model in Bangladesh to determine how these barriers could be overcome by the implementation of a model similar to the Grameen Shakti-IDCOL model.

\section{- The subsidy policy is ineffective and inefficient and needs reform}

This refers to subsidies for the grid connected electricity, which is avoided by the use of Grameen Shakti-IDCOL products such as SHSs. In addition to the recommended reform of the subsidy of gridconnected electricity, the Grameen Shakti-IDCOL model utilised subsidies at the start of the program of US\$90 per SHS, which was reduced to US\$25 per SHS and it planned to be totally eliminated in the next few years. This is possible as the subsidy for SHS increases the market volume, which in turn 
reduces costs of SHS (due to economies of scale and business development) and the need for subsidies. The elimination of subsidies is not expected to hurt the market growth, as the decreasing trend in costs of SHSs is assumed to continue and to account for this reduction of subsidy. The subsidy policy of the Grameen Shakti-IDCOL model is that subsidies should only be utilised if they are likely to lead to sustainable markets, with conditions in which subsidies are no longer needed, such as building up initial market volume, local expertise, user awareness, appropriate technology adaptation, quality standards and entrepreneurial activities (Sharif, 2013).

\section{- Lack of financial incentives for private investors}

The Grameen Shakti-IDCOL model successfully developed the private sector of SHS into a \$200 million market. The use of fiscal support from the government encourages private investors in the field of SHS, in terms of both SHS suppliers and manufacturers. The use of subsidies to create a competitive market also is a financial incentive to SHS component suppliers.

\section{- Lack of effective quality and efficiency standards}

One of the key aspects of the Grameen Shakti-IDCOL model is the superior quality control and after sales service. The quality of SHS components, and the repair and maintenance service offered by GS and other POs in Bangladesh is monitored by quality inspectors of IDCOL. Random checks of systems are also carried out by both IDCOL officials and independent technical auditors. In addition, minimum warranties required are 20 years for the solar panel, 5 years for battery and 3 years for the charger with opportunities for customers to register any questions lodge complaints to a dedicated IDCOL call centre.

\section{- Energy efficient products are expensive due to a limited market}

The use of subsidies and the creation of a large market with many suppliers and POs ensures healthy competition and low prices per SHS. As mentioned, smart subsidies have helped to build the SHS market in Bangladesh to a point where economies of scale and local expertise have reduced prices to a very competitive price. Technical and quality standards should help facilitate access to energy efficient products that are cost competitive.

\section{- Lack of rural electrification law}

One prominent aspect of the development of rural electrification law in Bangladesh was the use of subsidies. The Rural Electrification and Renewable Energy Development (RERED) program was introduced in Bangladesh on December 31, 2002, which included subsidies for SHSs, effectively lowering the prices of SHSs for customers. This was a key factor to increasing market size and growth of the sector in Bangladesh. A similar subsidy scheme is predicted to have a similar positive impact in Myanmar, if appropriately coupled with the development of an initiative similar to Grameen ShaktiIDCOL.

\section{- Lack of regulation for mini-grid systems}

A key aspect of the Grameen Shakti-IDCOL model was the stringent quality and efficiency standards as well as effective after sales services for SHSs and mini-grid systems. As shown in Figure 4, suppliers must have equipment approved by a technical standards committee before it is sold by Grameen Shakti. However, it is also recognised by Grameen Shakti and IDCOL that there is a prevalence of poor quality SHSs outside the Grameen Shakti-IDCOL program. Better regulation of these low cost, potentially unsafe systems outside the program is therefore also recommended. 
In summary, some of the key factors to the success of this model are the innovative financing structure, financial contribution of all parties, sustainable business model, superior quality control and after sales service, price determination by the market, cost-efficient standardised technical design, development of local support industries, Bangladesh's microfinance experience, and support from government and development partners. These key factors have great potential for application in Myanmar, to overcome some key barriers and limitations to electrification of Myanmar.

However, challenges facing the program includes, low efficiency of collection efficiency due to political instability in some areas and poor performance of some partner organisations, lack of supplier's accountability and the prevalence of poor quality and low cost SHS outside the program market.

\subsection{Sustainable energy for rural poor: Analysis and lessons learned}

In addition to Grameen Shakti-IDCOL model, the United Nations, World Bank, as well as various NGOs and governments have attempted with varying levels of success to develop models of sustainable energy for the rural poor around the world using a range of different technologies, implementing various strategies and financing mechanisms. Many lessons have been learned and progress has been made in developing an effective model, and a brief summary of some of the key learnings from these projects is provided below.

\subsubsection{Financial considerations}

The unaffordability of Renewable Energy Technologies (RETs), due to high capital costs, is the main constraint for many rural poor, who, as previously mentioned, have very little disposable income and spend very little on energy. Financial institutions are often unwilling to lend to the rural poor to overcome this constraint, and on the other hand, local manufacturers or dealers of RETs also face challenges in obtaining loans. These local dealers also face geographic barriers, which make developing sales and marketing infrastructure difficult. Microfinance was found to be a critical input for success in several projects, as it allows users to gain ownership of the system (Alazraque-Cherni, 2008; Laufer \& Schafer, 2011), and does not rely on ongoing donations, but rather creates a selfsustaining business model.

The current electricity tariff in Myanmar is segregated by consumption, and is shown in the table 3 below.

\begin{tabular}{|l|l|l|}
\hline $\begin{array}{l}\text { Consumption } \\
\text { (kWh/month) }\end{array}$ & Tariff (MMK/kWh) & Tariff (USD/kWh) \\
\hline$<100$ & 35 & 0.04 \\
\hline $100-200$ & 40 & 0.05 \\
\hline$>200$ & 50 & 0.06 \\
\hline $\begin{array}{l}\text { Connection } \\
\text { type }\end{array}$ & $\begin{array}{l}\text { Cost of connection } \\
\text { (MMK) }\end{array}$ & $\begin{array}{l}\text { Cost of } \\
\text { connection (USD) }\end{array}$ \\
\hline Legal & $100,000-300,000$ & $77-230$ \\
\hline $\begin{array}{l}\text { Illegal (before } \\
\text { meter box) }\end{array}$ & $15,000-20,000$ & $10-17$ \\
\hline
\end{tabular}

Table 3: Electricity tariff in Myanmar (KWR, 2015) 
These very low tariffs combined with illegal connections mean that essentially electricity is sold at a loss, so grid extension is very difficult to finance (KWR, 2015).

An important note should be made about poverty alleviation - electrification by itself will not lead to poverty reduction, but can assist in income generation, and must be incorporated into a wider poverty alleviation plan.

\subsubsection{Technological aspects}

A lack of local technical expertise is often a barrier, which can lead to design of inefficient or inappropriate systems which can lead to excessive costs and/or operational failure. Indeed, one of the recurring themes from past projects was that effective after sales support is essential, which should include: maintenance, repair, replacement of inoperable equipment, warranty, auditing and quality control, service, and training on the proper use of the system (Alazraque-Cherni, 2008; IGES, 2005; Biswas et al, 2001). This after sales support should be included in the total loan (Sovacool \& Drupady, 2011), to avoid unexpected costs later in the period, and all equipment should be under warranty for the life of the loan. An important aspect to ensure that the system is well-kept and maintained by the community or household is to create motivation, involvement and a sense of ownership among beneficiaries.

The three sources of renewable energy which could play a major part due to being established technologies and Myanmar having abundant resources are biomass, water (hydroelectricity) and solar. Major biomass residues are available in Myanmar, including paddy husk, straw, fuelwood and bamboo (Tippayawong et al, 2009). Hydroelectricity could be most suited to Kachin, Shan and Kayin states, where there is significant resource potential (DRD, 2014). In terms of levelised cost of electricity (LCOE), small hydro has the lowest for off-grid, followed by PV, and then diesel generators (Kumar, 2015). Currently, many small hydro projects in Myanmar suffer from poor safety levels and bad efficiency, leading to excessive costs (Ajith-Kumara, 2015). Potential solar energy of Myanmar is $51,973 \mathrm{TWh} / \mathrm{yr}$, and most of Myanmar receives between 4.4-5.2 kWh/m2/day all year round, with the worst months being the rainy season of July, August and September, and the best being the dry season of April, March and February (IGES, 2014; Nai, 2014). In this way, solar energy has potential to be an effective combination with hydroelectric power, which produces the most energy in the rainy season.

The companies currently installing the most SHS include SolRiseSys, Asia Solar, Earth Renewable Energy Company, T \& t Co. Ltd, Moe Ko San Solar, and Myanmar Mahar Htun (Greacen, 2015b). Many technical issues for SHS were discovered, including poor wiring, poor safety, poor solar panel performance, and high rates of failure in controller, inverter, batteries and lighting. Challenges to companies include a wide variety of experience levels (0-12 years), difficult to stay in business at US\$160/SHS (200,000 kyat), difficult to honour warranty considering transaction costs to rural sites, and cashflow challenges (Greacen, 2015a).

\subsubsection{Institutional framework}

It is essential that the institutional framework of Myanmar has the capacity to foster the electrification of the country in an efficient and sustainable manner. This can be done by developing a transparent and reliable rural electrification plan, a feasible framework and a central entity to 
coordinate rural electrification activities in order to avoid duplication and overlap (EUEI, 2013). Institutions will play a key role in delivering the NEP, by ensuring the effective flow of funds into the program, by coordinating the program in a least-cost basis and by ensuring projects are being built efficiently and are achieving social objectives (Castalia Advisors, 2014). The delivering of the NEP must include a clear pathway for private sector involvement (Castalia Advisors, 2014), as well as inclusion of all relevant stakeholders, including but not limited to government, development partners, utilities, regulatory authorities, local governments, sector ministries and consumers (World Bank, 2014a). It is worthy to note that the NEP has a significant drawback in that it entails no specific focus on energy access to the poor within its nine point plan (Kumar et al., 2015).

Two of the most relevant ministries for energy matters are the ministry for livestock, fisheries and rural development (MLFRD) and the ministry of electric power (MOEP), however other ministries like industry, science and technology, and mines are also relevant. Intra-ministerial coordination is crucial to effective policy making (KWR, 2015). Rural electrification is driven by MLFRD, including the allocation of funds, negotiating with international investment grants and loans and cooperating with NGOs, donors and PPPs (DRD, 2015). The institution responsible for energy sector policy implementation is the National Energy Management Committee and is supported by the Energy Development Committee (MOEP, 2013a). The creation of these institutions are signs of positive progress, but in order to supervise the ongoing implementation process, they will need to be institutionalised and structured with effective coordination and clearly defined coordination of roles and responsibilities (KWR, 2015). There is still a fragmented and overlapping policy/organisation situation in Myanmar (Kumar et al., 2015).

The coordination and allocation of funding on a sector-wide basis, is essential (Castalia Advisors, 2014). One of the most important differences between countries that have succeeded in electrification (such as Philippines, Thailand, Lao PDR and Indonesia) and countries that have not (Myanmar and Cambodia), is that there should be clear institutional arrangements, with an entity assigned to electrification and clear funding allocation (Guzman, 2013). Currently, Myanmar's institutional arrangements are designed to support electrification expansion on an ad hoc projectby-project basis, which leads to funding being fragmented and inefficient.

\subsubsection{Socio-cultural and other factors}

It is essential that the PO has a polycentric structure, with a strong local presence, to understand the needs and issues of the local population and to be familiar with local conditions and procedures (IGES, 2005; Biswas, 2001; Khan \& Rabbi, 2013). This also creates an atmosphere of trust and reliability between IAs and other stakeholders, and can assist in strengthening regional networks and partnerships (WHO, 2014). The PO needs to have a commitment to the region and/or technology beyond the length of the project (Laufer \& Schafer, 2011). A study in Shwe Pyi Thar Township found that the primary reason for using inferior forms of energy was the apparent high upfront cost of alternatives in these communities (Kumar, 2015) compared to global trends where evidence show a decline in cost of some renewables such as solar photovoltaic. Local capacity building and demonstrations on how to operate the technology and well as support systems for repairs and maintenance should be provided. (Laufer, \& Schafer, 2011; Sovacool \& Drupady, 2011). 


\subsection{Institutional framework}

Firstly, there are several recommendations regarding the institutional framework of Myanmar's electricity sector, from various sources (KWR, 2015; EUEI, 2013; Castalia Advisors, 2014). Generally, it is recommended that there is better coordination between ministries, national and regional governments, and between government, private and international agencies (KWR, 2015), with clearly defined roles and responsibilities of all involved stakeholders (EUEl, 2013). It is also recommended that there is a mechanism put in place to coordinate and allocate various financing and funding sources into a coherent and comprehensive program on a sector-wide basis (Castalia Advisors, 2014).

Establishing a well-resourced executive secretariat that reports to the vice president or president, and assists in overall coordination and management of the NEP in Myanmar has been suggested (World Bank, 2014a). The main tasks recommended for the executive secretariat are "to maintain and update geospatial and financial plans for the NEP, monitor achievement targets, serve as a main point of contact for development partners, advise on management of coherent financing program, and to provide advice and support to ministries involved in the NEP implementation" (World Bank, 2014a).

In addition to this, the renewable energy plan should be incorporated in a wider plan, which jointly addresses other needs such as livelihood improvement, sustainable agriculture and/or capacity building (Liming, 2008). It is essential to use an "Energy Plus approach", which aims to combine capacity development and productive uses of energy for income generation (Kumar, 2015).

\subsection{National electrification plan}

To make the national electrification plan more economical for both demand and supply sides, a reassessment of electrification options should be undertaken, with an adjusted SHS price and to include the cost of additional generation for households to be connected to the grid. SHS installation costs are cheaper than grid connection (and without the cost of electricity afterwards) for customers, and it may be cheaper and preferable for rural poor, with low demand for electricity, to own SHS rather than to connect to the grid in the immediate term. However with an opportunity for micro-grid or even grid connections over time based on their demand and the ability to pay the micro-grid or grid tariff. The ambitions for less than 100,000 SHSs to be installed, with roughly $98 \%$ of these for "pre-electrification" to be replaced by grid extension in 15 years or longer, seem to pale in comparison with the success of the SHS program of neighbouring Bangladesh.

It is therefore recommended that there is a wider implementation of SHSs, with a more ambitious target, building on lessons learned from Grameen Shakti-IDCOL. For example, the pre-electrification program could be expanded to include Phase 4 (615,000 households @ \$1,030 per household connection cost) and phase 5 (234,000 households at $\$ 1,710$ per household connection cost) (Figure 5). These households could be supplied by either mini-grids or SHS, depending on the size of the village, but using the same ratio as the existing pre-electrification program it would be assumed that of the 840,000 households in these phases, 500,000 would be supplied by mini-grids and 340,000 to be supplied by SHSs (Figure 5). The SHSs should be designed so that they may be connected to the 
grid when it is eventually rolled out (in addition to the mini-grids which have been recommended to the designed for eventual grid connection). As the NEP is evaluated over time, the progress of the grid extension and the progress of the SHS and mini-grid installations should be evaluated over time and decisions can be made on an ongoing basis as to whether to increase the rate of off-grid electricity or grid connection.

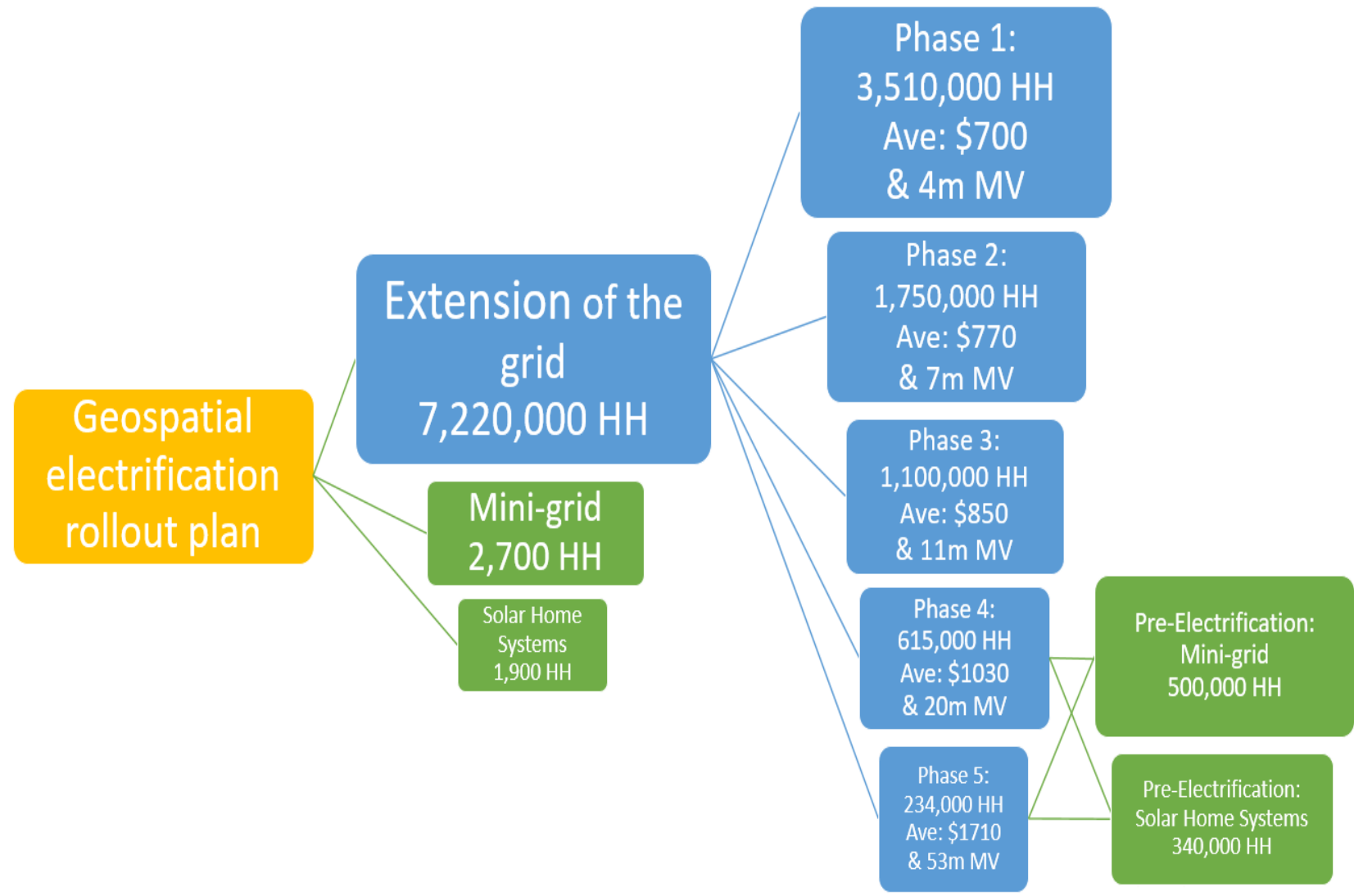

Figure 5: Potential expansion of pre-electrification in the geospatial electrification rollout plan

\subsection{Tariff/subsidy review}

It is recommended to review the existing tariff and subsidy mechanism (World Bank, 2014b). These policies should be updated to target the poor (Kumar, 2015), while simultaneously targeting greater returns to fund grid extension so electricity is no longer sold at a loss.

\subsection{Public-Private Partnerships (PPPs)}

Public-private partnerships (PPPs) have been successful in developing energy systems, such as IDCOL in Bangladesh, and should be encouraged in Myanmar (IGES, 2014). In the energy sector, PPPs have significant potential in both the demand side (capacity building, technical and financial assistance, project coordination, quality assurance) and the supply side (manufacturing, installation, after sales service and internal quality control) (Dhital, 2015).

\subsection{Microfinance Institution}


It is recommended that micro-financing, which has proven very successful in many developing countries such as Bangladesh and Sri Lanka, be developed in Myanmar (Kumar, 2015). In particular, microfinance institutions (MFIs) who can promote microfinance of SHS could be very effective (IGES, 2014). The MFI should have a number of qualities to ensure its success.

The distribution of responsibilities (financial and technical separate into two entities) leads to higher costs (IGES, 2005) so it is recommended that the financing and technical responsibilities are handled by one institution, whether it be an existing, trusted energy NGO that takes on microfinancing responsibilities, or a MFI delivering energy services such as Grameen Shakti (the PO). This allows e.g. the loan collection and maintenance to be undertaken at the same time, and costs are thus reduced. Also, realistic expectations regarding market development are important - it will take some time to build capacity (policy, institutional and financing framework) (Alazraque-Cherni, 2008).

Economic sustainability should be sought after, by means of consumer friendly practices and carbon offsets from reducing GHGs. Consumer friendly practices should be implemented as much as possible, such as a decentralised bottom up approach that encourages a culture of listening to customers and improving from feedback, utilizing community based social engineers who understand rural people, education about RETs for school children, buy-back systems and removal of dead batteries and social commitment by creating jobs for local youth and women (Laufer, \& Schafer, 2011). Effective after sales support and communication with government are both important to avoid situations where the consumer will not pay, such as if the system becomes inoperable or if the government connects the household to the grid (IGES, 2005). Negative experiences not only retract from the customer's experience, but damage the reputation of the program, hindering further opportunities to expand.

As mentioned, it is essential that the PO has a polycentric structure, with a strong local presence, to understand the needs and issues of the local population and to be familiar with local conditions and procedures (IGES, 2005; Biswas, 2001; Khan \& Rabbi, 2013). This also creates an atmosphere of trust and reliability between IAs and other stakeholders, and can assist in strengthening regional networks and partnerships (WHO, 2014). Ethical issues can be somewhat avoided by a local network, although there needs to be strong governance of the microfinance sector to ensure ethical operation. The PO needs to have a commitment to the region and/or technology beyond the length of the project, and having a local presence ensures this (Laufer, \& Schafer, 2011).

Local demonstrations should be held to display how the technology works and how it can be financed (Laufer \& Schafer, 2011; Sovacool \& Drupady, 2011) to overcome the constraint of lack of awareness of the technologies. The local human resources should be tapped as much as possible, for example community leaders, institutions and market forces (Terrapon-Pfaff et al., 2014).

\subsection{Technical considerations}

It has been recommended that there is increased energy performance requirements or labels, and other energy efficiency measures (Myint, 2012). The Department of Rural Development specifications for all components in SHS for achieving subsidy standards must be revised and updated, possibly using IDCOL standards (Greacen, 2015a). The goal of these updates should be to increase reliability, efficiency and safety of the SHSs.

Greacen (2015a), after a review of the DRD SHS program, has recommended that the DRD SHS of an 80-90Wp panel, with 65 Ah battery, 20 watts CFL lamp, with 300 W inverter, be replaced with a 60 
Wp panel, 60 Ah battery, 8-10 watts LED, without an inverter, but with quality standards including certified components, adequate wiring, proper installation and warranty (Greacen, 2015a;

Tippayawong, 2009), as shown in Figure 6 . The replaced system costs roughly $\$ 160$, so the new system, without the cost of the inverter, would cost even less. This however suggests that the assumptions made in the least cost geospatial electrification rollout plan ( $\$ 450-500$ for $80-100 \mathrm{Wp})$, are perhaps excessive, which may partly explain why so few households are recommended to have SHS installed by the plan. The plan uses US\$0.13/kWh for long-term costs of installed new generation, compared to US\$0.57/ kWh for SHS. If these recommendations from Greacen (2015a) are undertaken, a more realistic cost of electricity in SHS might be roughly one third of the US\$0.57/kWh used, which would presumably increase the recommended share of SHS in the plan. Another important issue to be noted is that the least cost geospatial electrification plan compares SHS and mini-grid technologies (which include the generating cost of solar panels) to connection to the grid (which does not include the cost of additional required generation capacity). The plan for connection to the grid would require roughly double the current generation capacity, which would obviously entail a significant cost. Taking this into account, as well as the rather high assumed cost of SHS in the least cost electrification rollout plan, it is quite likely that SHS would actually be cheaper for many more households than the 1,900 and 95,000 for permanent SHS and "pre-electrification" SHS, as recommended in the plan. It is essential that these assumptions are taken into account and the total costs of energy are assessed - not only connection and distribution but generation well - if there is to be a relevant comparison.

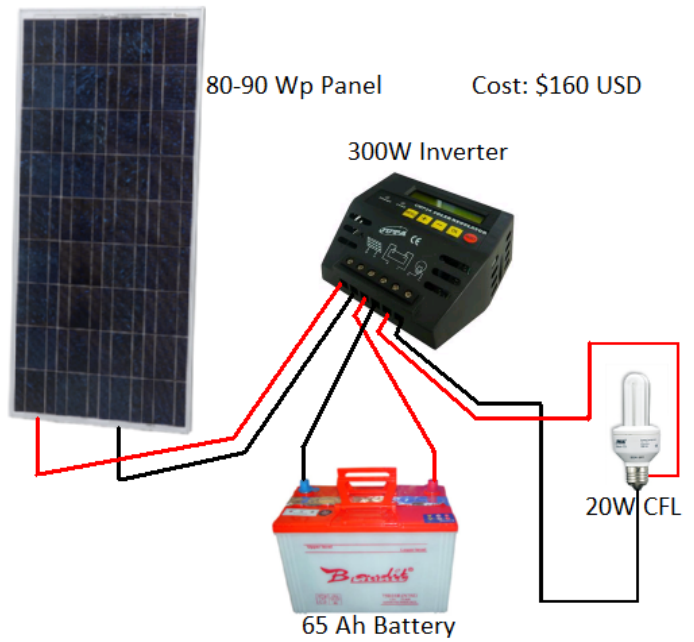

Existing System
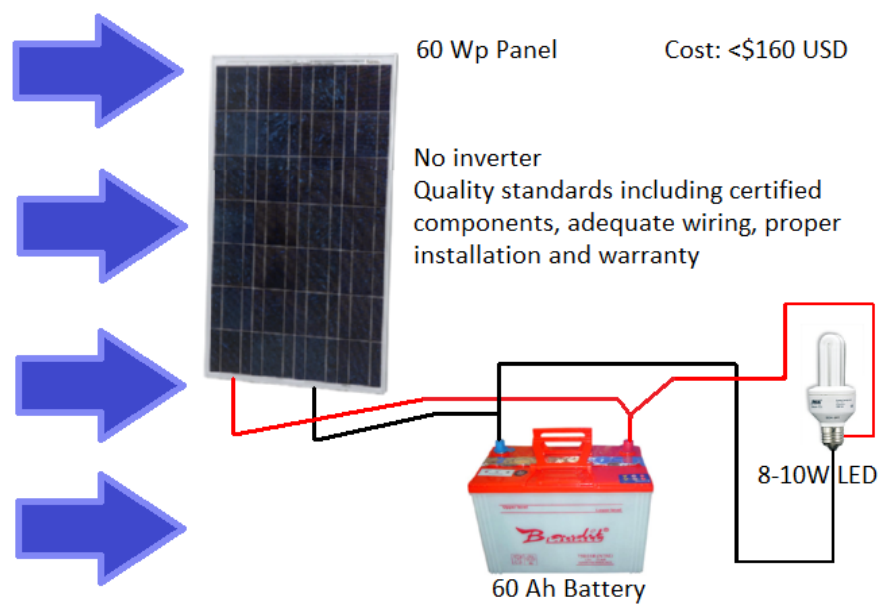

Recommended System

Figure 6: Existing SHS and recommended SHS by Greacen (2015a) 


\section{Conclusion}

A PPP and PO/NGO collaborative program, selling SHS to rural poor using microfinance has great potential to sustainably supply electricity to remote areas of Myanmar. This program could be a very economically efficient way to contribute both to the NEP's aim of universal electricity access by 2030 and to the goal of $15-18 \%$ renewable installed capacity by 2020. Myanmar has great potential, with a large population with low disposal income and no electricity access, as well as abundant sunlight, to benefit from a microfinance based SHS program. With adjustments to the institutional framework as mentioned in this paper, an enabling environment could be created, in which this PPP and PO/NGO collaborative program can flourish. In summary, the initial objectives of this paper have been fulfilled.

\section{- Analyse experience from Grameen Shakti-IDCOL and other similar projects for possible replicability lessons}

A multitude of financial, technological, institutional and social/cultural lessons learned have been summarised from Grameen Shakti-IDCOL and similar initiatives. Some key lessons learned were the importance of local training and stakeholders' involvement, the potential of microfinancing to open up electricity access to new poor rural populations, as well as the importance of effective coordination between ministries.

\section{- Identify barriers to sustainable electrification for rural areas of Myanmar}

Barriers to sustainable electrification in rural areas of Myanmar were identified. Major barriers to increased electrification in rural areas were a dispersed rural population, lack of local technical expertise and lack of affordability. However, these could be overcome by using regional offices, training local people and ethical and affordable microfinancing plans.

- Replication of lessons learned and experience to develop policy recommendations to overcome barriers to sustainable electrification for rural poor in Myanmar

A PPP-NGO/PO program using microfinance to deliver solar home systems, is recommended to increase access to electricity to rural poor in Myanmar. It is recommended that there is better coordination between ministries, and a reassessment of electrification options for rural poor. The electricity tariff and subsidies could possibly be reviewed in order to be economically sustainable. It is also recommended that the solar home system specifications used by the Department of Rural Development are reviewed. Two key limitations of the least cost electrification rollout plan were identified in the high cost of SHSs and the exclusion of generating costs for conventional generation, and it is recommended that these are considered for the future of Myanmar's rural electricity access.

Further studies should focus on the productive use of energy for income generation. It is crucial to ensure houses which have SHSs installed are prepared for the next step, whether it be grid connection or mini-grids. It is recommended therefore that there is more detailed analysis on how electricity access can be combined with productive use for income generation and poverty alleviation. 


\section{Acknowledgements}

This research did not receive any specific grant from funding agencies in the public, commercial, or not-for-profit sectors.

\section{Disclaimer}

The opinions and recommendations expressed in this report are those of the authors and do not necessarily reflect those of UNEP DTU Partnership (UDP) nor DTU. The designations employed and the presentation of the material in this publication do not imply the expression of any opinion whatsoever on the part of UDP or DTU concerning the legal status of any country, territory, city or area or of its authorities.

\section{References}

Ajith Kumara, P. G., 2015. Off-grid Hydropower Status of Myanmar - NEP Workshop on Off-grid Electrification in Myanmar.

https://energypedia.info/wiki/Achieving_Universal_Access_to_Electricity_in_Myanmar (accessed 20.02.16).

Alazraque-Cherni, J., 2008. Renewable Energy for Rural Sustainability in Developing Countries. Bulletin of Science Technology \& Society 28, 105-114.

ArcFinance, 2014. Going "All in" on Solar Finance: How IDCOL Incubates a Growing Industry in Bangladesh. http://arcfinance.org/news/blog/going-all-in-on-solar-finance-how-idcol-incubates-agrowing-industry-in-bangladesh/ (accessed 20.04.16).

Asian Development Bank, 2015. Myanmar: Off-grid Renewable Energy Demonstration Project. http://www.adb.org/projects/47128-001/main (accessed 27.03.16).

Biswas, W. K., Bryce, P., Diesendorf, M., 2001. Model for empowering rural poor through renewable energy technologies in Bangladesh. Environmental Science \& Policy 4, 333-334.

Castalia Advisors, 2014. Myanmar National Electrification Program (NEP) Roadmap and Investment Prospectus. https://energypedia.info/wiki/Achieving_Universal_Access_to_Electricity_in_Myanmar (accessed 07.02.16).

Department of Rural Development - Ministry of Livestock, Fisheries and Rural Development, 2014. Rural Electricity Access.

https://energypedia.info/wiki/Achieving_Universal_Access_to_Electricity_in_Myanmar (accessed 17.02.16).

Department of Rural Development - Ministry of Livestock, Fisheries and Rural Development, 2015. Rural Electricity Access.

https://energypedia.info/wiki/Achieving_Universal_Access_to_Electricity_in_Myanmar (accessed 17.04.16).

Dhital, R. P., 2015. Experiences Sharing on Micro-Mini Hydro Power Development in Nepal Workshop of Off-grid Electrification in Myanmar. https://energypedia.info/wiki/Achieving_Universal_Access_to_Electricity_in_Myanmar (accessed 12.05.16). 
Columbia University, Earth Institute - Sustainable Engineering Lab, 2014. Myanmar National Electrification Plan (NEP): Least-Cost Geospatial Electrification Planning Results.

https://energypedia.info/wiki/Achieving_Universal_Access_to_Electricity_in_Myanmar (accessed 05.04.16).

European Union Energy Initiative, 2013. Myanmar - Rural Electrification Workshop. International Best Practices and Options for Policy Makers. http://www.euei-

pdf.org/sites/default/files/files/field_pblctn_file/EUEl\%2OPDF_Myanmar_Workshop\%20Rural\%20EI ectrification_Jun2013_EN.pdf (accessed 02.03.16).

GNESD 2015. Country report (Myanmar). Urban and Peri-urban Energy Access in Myanmar: Knowledge and Outreach. Report prepared for the Global Network on Energy for Sustainable Development by the Asian Institute of Technology

http://www.gnesd.org/PUBLICATIONS/Energy-Plus

Government of the Republic of the Union of Myanmar, 2015. Myanmar's Intended Nationally Determined Contribution-INDC.

http://www4.unfccc.int/submissions/INDC/Published\%20Documents/Myanmar/1/Myanmar's\%20IN DC.pdf (accessed 14.03.16).

Greacen, C., 2015. DRD Solar Home Systems (SHS) in Myanmar: Status and Recommendations Report to the World Bank.

https://energypedia.info/wiki/Achieving_Universal_Access_to_Electricity_in_Myanmar (accessed 27.01.16).

Greacen, C., 2015. DRD Solar Home Systems in Myanmar: Findings from Nov/Dec 2014 Field Visit NEP Workshop on Off-grid Electrification in Myanmar.

https://energypedia.info/wiki/Achieving_Universal_Access_to_Electricity_in_Myanmar (accessed 28.01.16).

Guzman, A., 2013. Institutional Framework and Business Models - Approach and Methodology. https://energypedia.info/wiki/Achieving_Universal_Access_to_Electricity_in_Myanmar (accessed 22.03.16).

Haque, N., 2015. IDCOL Solar Home System Program. Off-grid Electrification Workshop. https://energypedia.info/wiki/Achieving_Universal_Access_to_Electricity_in_Myanmar (accessed 02.03.16).

IndexMundi.com, 2015. Myanmar - Access to Electricity.

http://www.indexmundi.com/facts/myanmar/access-to-electricity (accessed 04.03.16).

Institute for Global Environmental Strategies, 2005. Innovative financing for renewable energy development.

http://enviroscope.iges.or.jp/contents/APEIS/RISPO/p_report_2nd/06_3_2_1_innovative_financing _for_renewable_energy.pdf (accessed 11.04.16).

Institute for Global Environmental Strategies, 2014. Supporting low-carbon Yangon city through Joint Crediting Mechanism (JCM) project formulation. Feasibility Studies on Joint Crediting Mechanism Projects towards Environmentally Sustainable Cities in Asia. https://www.env.go.jp/earth/coop/lowcarbon-asia/english/project/data/jcm_pamphlet.pdf (accessed 11.03.16). 
International Energy Agency, 2015. Southeast Asia Energy Outlook. https://www.iea.org/publications/freepublications/publication/WEO2015_SouthEastAsia.pdf (accessed 27.01.16).

Khan, S. I., Rabbi, F., 2013. An Innovative Financing Mechanism: Creating Access to Renewable Energy for Rural people of Bangladesh.

https://sustainabledevelopment.un.org/content/documents/4927khan.pdf (accessed 27.03.16).

Kumar, A., 2015. State of Art Minihydro Technologies for Electrification - Workshop of Off-grid Electrification in Myanmar.

https://energypedia.info/wiki/Achieving_Universal_Access_to_Electricity_in_Myanmar (accessed 20.02.16).

KWR International (Asia) Pte. Ltd., 2015. Turning on the Lights: Integrated Energy and Rural Electrification Development in Myanmar - the Critical Importance of Power Development. http://kwrintl.com/library/2015/1KWRERIASummary-MyanmarElectrification.pdf (accessed 14.03.16).

Larsen, T.H., Ackom, E.K., Mackenzie, G.A. 2016. Sustaining Energy Access: Lessons from Energy Plus Approach and Productive Use in developing countries. Global Network on Energy for Sustainable Development (GNESD). Summary for policymakers (SPM). GNESD-SPM-E-Plus-12/2015.

Laufer, D., Schafer, M., 2011. The implementation of Solar Home Systems as a poverty reduction strategy - a case study in Sri Lanka. Energy for Sustainable Development 15, 330-336.

Liming, H., 2008. Financing Rural Renewable Energy: A Comparison between China and India. http://www.frankhaugwitz.info/doks/general/2008_05_23_China_RE_Finance_Comparison_India.p df (accessed 12.02.16).

Ministry of Electric Power - Myanmar Electric Power Enterprise, 2013. Power System Development Scheme of MEPE.

https://energypedia.info/wiki/Achieving_Universal_Access_to_Electricity_in_Myanmar (accessed 18.04.16).

Ministry of Electric Power, 2013. Present \& Future Power Sector Development in Myanmar. https://energypedia.info/wiki/Achieving_Universal_Access_to_Electricity_in_Myanmar (accessed 17.04.16).

Myanmar Times, 2015. World Bank Approves $\$ 400 m$ electrification loan. http://www.mmtimes.com/index.php/business/16556-world-bank-approves-400m-electrificationloan.html (accessed 20.05.16).

Myint, A., 2012. Rural Electrification and Access to Electricity in Myanmar - Ministry of Electric Power https://energypedia.info/wiki/Achieving_Universal_Access_to_Electricity_in_Myanmar (accessed 22.03.16).

Nai, C. C., 2014. ADB's Energy Program in Myanmar.

https://energypedia.info/images/0/06/5_ADB_presentation_at_WB_NEP_workshop_March20_2014 _CCN_final_pm.pdf (accessed 28.03.16).

Pascale, A., Urmee, T., Whale, J. \& Kumar, S., 2016. Examining the potential for developing womenled solar PV enterprises in rural Myanmar. Renewable and Sustainable Energy Reviews 57 (2016) 576-583. 
Pode, R., 2015. Battery charging stations for home lighting in Mekong region Countries. Renewable and Sustainable Energy Reviews 44, 543-560.

Schmitt-Degenhardt, S., 2013. A Regional Perspective on Poverty in Myanmar - UNDP. http://www.se.undp.org/content/dam/sweden/Rapporter/A\%20regional\%20perspective\%20on\%20 poverty\%20in\%20Myanmar.pdf (accessed 16.04.16).

Sharif, I., 2013. Rural Electrification: the success story of Bangladesh.

https://cleanenergysolutions.org/sites/default/files/documents/Islam-Sharif-SKJ-Bangladesh-UN.pdf (accessed 20.02.16).

Singh, R., Wang, X., Mendoza, J.C., Ackom, E.K. (2014). Electricity (in)accessibility to the urban poor in developing countries. WIREs Energy Environ 2014. doi: 10.1002/wene.148

Sovacool, B., Drupady, I. M., 2011. Summoning earth and fire: the energy development implications of Grameen Shakti (GS) in Bangladesh. Energy 36, 4445-4459.

Terrapon-Pfaff, J., Diesnst, C., Konig, J., Ortiz, W., 2014. A Cross-sectional review: Impacts and sustainability of small-scale renewable energy projects in developing countries. Renewable and Sustainable Energy Reviews 40, 1-10.

Tippayawong, N., Chaichana, C., Swee, M. L., 2009. Distributed Electricity Generation from Biomass Gasification as a Sustainable Energy Option for Rural Myanmar. International Journal of Distributed Energy Resources 5, 71-82.

UNDP 2012. Towards an 'Energy Plus' Approach for the Poor: A Review of Good Practices and Lessons Learned from Asia and the Pacific. UNDP. January 2012.

UN FPA, 2010. Report on Situation Analysis of Population and Development, Reproductive Health and Gender in Myanmar. https://www.unfpa.org/sites/default/files/admin-resource/MyanmarReport-on-Situation-Analysis-of-Population-and-Development-Reproductive-Health-and-Gender-inMyanmar.pdf (accessed 10.03.16).

Velumail T, Turton C, Beresnev N. 2015. The energy plus approach In Halff A, Sovacool B J, Rozhon J (eds). Energy poverty Oxford University Press 459pp.

Win, Z. M., 2013. Experience with Grid and Off-grid Rural Electrification in Myanmar - Ministry of Electric Power.

https://energypedia.info/wiki/Achieving_Universal_Access_to_Electricity_in_Myanmar (accessed 20.04.16).

World Bank, 2016. Data - Electric power consumption (kWh per capita). data.worldbank.org. (accessed 16.02.16).

World Bank, 2014a. Myanmar: Towards Universal Access to Electricity by 2030. https://www.esmap.org/sites/esmap.org/files/DocumentLibrary/Myanmar\%20NEP\%20BBL\%20pres enation\%2010-01-2014.pdf (accessed 03.02.16).

World Bank, 2014b. Poverty and Social Impacts Analysis - Understanding the impact of tariffs and connection costs for the preparation of the National Electrification Plan, Myanmar https://energypedia.info/images/5/50/Final_PSIA_Draft_Qualitative_Analysis_09-222014_ExecSummary.docx (accessed 14.04.16). 
World Health Organisation, 2014. Household Air Pollution and Health Fact Sheet. http://www.who.int/mediacentre/factsheets/fs292/en/ 